\title{
Erratum to: Would Human Extinction Be Morally Wrong?
}

\section{Franco Palazzi}

Published online: 20 December 2014

(C) Springer Science+Business Media Dordrecht 2014

\section{Erratum to: Philosophia (2014) 42:1063-1084 \\ DOI 10.1007/s11406-014-9553-7}

The original version of this article unfortunately includes some imperfections. The correct details are given below.

In the second paragraph of the text, references to Leslie 2002 are actually to Leslie 1996.

At note 23 , the sentence "even if in so doing I would not make A's condition overall worse" should be replaced by "even if in so doing I would not make B's condition overall worse"; in the following period, an "if" should be inserted between "even" and "it".

In the last page of the third paragraph, the sentence "would result in a strong violation of some kind of duty toward already existing people than" is intended substituted by the following one: "would result in a violation of some kind of duty toward already existing people, then,".

\footnotetext{
The online version of the original article can be found at http://dx.doi.org/10.1007/s11406-014-9553-7.

F. Palazzi $(\bowtie)$

Political Science, Sant'Anna School of Undergraduate and Postgraduate Studies, Collegio Alessandro

Faedo, via Del Giardino 3, Pisa, Italy

e-mail: f.palazzi@sssup.it

F. Palazzi

e-mail: francopalazzi@hotmail.it
} 